\title{
De opkomst, bloei en ondergang van het videojournaal
}

‘(...) met behulp van interne video's kan het management veel onwetendheid en onnodige onrust wegnemen (.... ${ }^{\text {'I }}$ Siebrand Vos in het Nieuwsblad van het Noorden

Op I4 januari I978 kondigde De telegraaf op zijn financiële pagina aan dat het 'de hand [heeft] gelegd op roo exemplaren' van een Amerikaanse publicatie met de titel Private Television Communications: An Awakening Giant. Het boek werd 'de geïnteresseerde lezer (...) aangeboden voor $f 90$ per stuk, inclusief verzendkosten en btw.' Het kon, aldus het dagblad dat er graag prat op ging 'de grootste krant van Nederland' te zijn, 'in deze tijd van keiharde internationale concurrentie (...) geen kwaad nieuwe ontwikkelingen, waaraan het Nederlandse bedrijfsleven iets kan hebben, te signaleren. Zo'n ontwikkeling is de stormachtige opmars van de z.g. bedrijfsvideo in de Verenigde Staten.' Tekenend voor die opmars noemde de krant 'het feit dat de markt voor bedrijfsvideo in de VS sinds I973 is verdubbeld tot \$500 miljoen.' Verder werd de president van chemiegigant DuPont aangehaald, die 'de bedrijfsvideo de beste en meest efficiënte manier [vindt] om communicatie binnen een bedrijf te plegen.' De Amerikaanse communicatieadviseurs Judith en Douglas Brush hadden van deze ontwikkelingen 'een grondige studie' gemaakt, getiteld Private Television Communications. Dit boek werd door De telegraaf geprezen als 'een prima vademecum (...) voor diegenen die bedrijfs-t.v. willen toepassen.'

Of De telegraaf alle honderd exemplaren is kwijtgeraakt is niet bekend. Feit is dat de krant na de eerste aankondiging nog slechts een paar advertenties plaatste voor het boek, waarvan ze de prijs overigens intussen wel verhoogd had naar $f$ ioo. Wie voelde zich geroepen om Private Television Communications aan te schaffen? De telegraaf mikte natuurlijk vooral op leidinggevenden uit het bedrijfsleven, voor wie de fikse prijs van het boek geen probleem zou moeten vormen. Private Television Communications was echter ook de moeite waard voor de Nederlandse opdrachtfilmers die sinds jaar en dag datzelfde bedrijfsleven van audiovisuele producties voorzagen.

De relatie tussen opdrachtgevers en bedrijfsfilmers was sinds 1973 geformaliseerd in de Stichting Audiovisuele Manifestaties (beter bekend onder het acroniem SAM), waarin het Verbond van Nederlandse Ondernemingen, het Christelijk Werkgeversverbond, de Amsterdamse Industrie Vereniging, Unilever, de bedrijfsafdeling Filmproductie van de Nederlandse Bioscoopbond (NBB) en het Technisch Filmcentrum vertegenwoordigd waren. ${ }^{3}$ De voornaamste activiteit van de SAM was de organisatie van de jaarlijkse manifestatie Opdrachtfilm, waarop de beste filmproducties in deze categorie werden vertoond, een vakjury 
prijzen toekende en de selectie van de Nederlandse inzendingen naar het Internationaal Industrieel Filmcongres werd gemaakt. Dit evenement had begin jaren zestig de plaats ingenomen van de klassieke filmfestivals als Cannes, Berlin en Venetië, waar in opdracht gemaakte Nederlandse documentaires zoveel successen hadden behaald. Het duurde tot I983, voordat de SAM erkende dat ook in opdracht gemaakte videoproducties tot haar terrein behoorde. Wat betekende de komst van video in de jaren zeventig en tachtig voor de opdrachtsector in Nederland? Wie profiteerden ervan en wie waren de verliezers? In dit artikel wordt gekeken hoe de introductie ervan verliep.

\section{Video}

De Nederlandse opdrachtsector behoorde bepaald niet tot de early adopters als het om video ging. Afgezien van de Nederlandse televisie die al vanaf I96r gebruik maakte van Ampex-apparatuur, was het in eerste instantie een kleine groep kunstenaars die zich begin jaren zeventig die rol toe-eigende. Hun grote voorbeeld was de Koreaans-Amerikaanse kunstenaar Nam June Paik die in I965 van Sony een Portapack kreeg en daarmee video's maakte. Op de expositie 'Sonsbeek buiten de perken' in I97I kon de buitenwereld voor het eerst met videokunst kennismaken. In 2003 beschreef kunsthistoricus Rob Perrée ‘Sonsbeek buiten de perken' als volgt:

Een van de onderdelen van de tentoonstelling was een tent waarin niet alleen video's werden getoond, maar waarin ook de mogelijkheid bestond video's te maken. Philips had gratis de apparatuur verstrekt voor deze provisorische studio. Geheel in de democratische geest van de tijd waren de camera's niet alleen beschikbaar voor kunstenaars (o.a. Shinkichi Tajiri, Nam June Paik en Stanley Brouwn), maar ook voor bezoekers. Het tot stand brengen van communicatie was het uitgangspunt. Een vorm van idealisme die toen nog niet het predikaat "naïef" verdiende. Hoewel er niet veel uitkwam (en veel van wat er uitkwam verloren is gegaan), was voor velen de kennismaking met het nieuwe medium een opwindende en stimulerende ervaring. Die opwinding resulteerde in verschillende initiatieven, die het begin vormden van een opmerkelijke ontwikkeling. ${ }^{4}$

Vanwege de kosten en het gecompliceerde karakter van de videotechnologie waren deze initiatieven collectief van aard en vonden onderdak in werkplaatsen of galerieën, zoals het Lijnbaancentrum in Rotterdam, Meatball in Den Haag, Galerie Agora in Maastricht en Open Studio en Galerie De Appel in Amsterdam. Sommige van deze initiatieven, zoals het Lijnbaancentrum, Meatball en Open Studio, waren niet alleen op kunstenaars gericht maar werkten ook samen met actiegroepen in de oude stadswijken. ${ }^{5}$ De achterliggende gedachte, dat video een democratisch medium was dat zich bij uitstek leende voor sociaal activisme, werd breed gedeeld, ook internationaal. Zo maakte de National Film Board of Canada (NFB) eind jaren zestig gebruik van video in het kader van haar beroemde 'Challenge for Change' programma. Actiegroepen in de mijnbouwstad Rosedale and in St. Jacques, een wijk van Montreal, kregen videoapparatuur van de NFB om opnamen te maken over zaken die speelden in hun buurt en de banden (de videocassette moest toen nog op de markt gebracht worden) vervolgens weer te laten zien aan de betrokkenen. Het idee was dat de kijkers inzagen dat zij niet de enigen waren die met 
bepaalde problemen te maken hadden en daarom gezamenlijk naar een oplossing gingen zoeken. Meer nog dan film beschouwde men bij de NFB video als een belangrijk middel om sociale veranderingen te bewerkstelligen. ${ }^{6}$

In Nederland deelde lang niet iedereen dit enthousiasme voor video. Progressieve collectieven als Cineclub, het Amsterdams Stadsjournaal, de Rode Lantaarn en de Kritiese Filmers gaven in de jaren zeventig de voorkeur aan $16 \mathrm{~mm}$ film, omdat ze de beeldkwaliteit ervan prefereerden. Video had dan ook last van een slecht imago: wazige beelden, slecht geluid en onzinnige dialogen en jargon. Kees van Kooten en Wim de Bie dreven er in I973 de spot mee in een sketch in Het gat van Nederland: 'Wat je mist aan kwaliteit, dat win je aan directheid met video.' Want, zoals Van Kooten opmerkte, 'Video ergo sum. ${ }^{7}$ Ook Jan Blokker stak er twee jaar later in zijn Volkskrant-column de draak mee:

Laatst zag ik nog een film. Hij was aan de basis gemaakt, zodat hij voornamelijk uit donkere vlekken bestond en ook wat het geluid betreft weinig uitkomst bood. Misschien was het ook wel een video-band, uit een workshop. Uit de napraat begreep ik dat hij een mechanisme had blootgelegd. ${ }^{8}$

Met zijn verwijzingen naar 'aan de basis gemaakt' en 'napraat' refereerde Blokker aan de populariteit van video op sociale academies en in vormingscentra. Er werden zelfs handboeken voor het gebruik van video door de medewerkers van deze instellingen gepubliceerd. ${ }^{9}$ Een andere ontwikkeling was de productie van videoprogramma's over lokale onderwerpen voor uitzending op de kabelnetwerken die in de jaren zeventig in een groeiend aantal gemeenten werden aangelegd. ${ }^{\text {Io }}$

Een derde groep van early adopters waren de universiteiten. Voor de komst van video was het relatief simpel geweest. Film was duur en vereiste specialistische kennis. Dus was de productie ervan ten behoeve van academisch onderwijs en onderzoek geconcentreerd in één instituut, de Stichting Film en Wetenschap (SFW) in Utrecht. In I970 betrok SFW een gloednieuw gebouw met alle mogelijke faciliteiten, tot een eigen televisiestudio aan toe.

Maar deze centralistische aanpak werd al snel verstoord door de komst van video. Elke universiteit wilde prompt zijn eigen audiovisuele dienst hebben om bijvoorbeeld closed circuit televisie te verzorgen bij bepaalde colleges of observerend onderzoek mogelijk te maken in de sociale wetenschappen. ${ }^{\text {II }}$ Zeker voor het uitbreken van de oliecrisis was het geen probleem om financiering voor dergelijke kostbare investeringen te krijgen van het ministerie van Onderwijs. Bekend werd de audiovisuele afdeling van het Medisch Centrum van de Erasmus Universiteit Rotterdam, die geleid werd door de 'televisiedokter' Aart Gisolf. ${ }^{\text {I2 }}$ Tonko Tomeï en Theo van der Biessen, die later een belangrijke rol zouden spelen in de opdrachtsector, deden hier hun eerste ervaringen op met audiovisuele productie.

\section{Opdrachtsector}

In de opdrachtsector werden deze ontwikkelingen met aandacht gevolgd, zoals blijkt uit de berichtgeving in de vakpers. Maar in plaats van enthousiasme voor het nieuwe medium video overheerste voorzichtigheid of zelfs regelrecht wantrouwen. De opdrachtfilmers waren van 
mening dat de kwaliteit van het videobeeld dermate inferieur aan het filmbeeld was dat het niet acceptabel was. Een tweede bezwaar gold het gebrek aan standaardisatie: de systemen waren niet uitwisselbaar en de formaten volgden elkaar in een razend tempo op. De keuze voor een bepaald systeem - met de hieraan verbonden hoge kosten - werd zo een gok. Een derde probleem vormde de lineaire montage die de creatieve mogelijkheden enorm beperkte. Dat was vooral moeilijk te verteren voor de oudere generatie opdrachtfilmers die was grootgebracht met het idee dat de kunst van het monteren de belangrijkste kwaliteit van een cineast was. ${ }^{\mathrm{I3}}$

Er waren enkele uitzonderingen. Zo produceerde Hoek en Sonépouse, een bedrijf dat volop profiteerde van de nieuwe ontwikkelingen op video- en televisiegebied, videoprogramma's met toeristische informatie, die hotels aan hun gasten konden laten zien op de televisie op hun kamer. Het was een interessant idee, alleen was anno I97I televisie op de kamer nog een echte luxe, die weinig hotels konden bieden, zodat de vraag naar Hotelvisie beperkt was. ${ }^{\text {I4 }}$ Thijs Chanowski, een producent die vooral voor de televisie werkte en een grote interesse had in nieuwe technologieën, introduceerde in diezelfde tijd Teletrip. Reisbureaus konden bij International Tourist Information SA, een onderneming waarin ondere andere de VNU deelnam, een speciaal toestel huren, waarop door Chanowski geproduceerde cassettes met informatie in beeld en geluid over bekende reisbestemmingen afgespeeld konden worden. ${ }^{15} \mathrm{Als}$ een van de weinigen onder de opdrachtfilmers zocht Chanowski nader contact met Philips om betrokken te zijn bij nieuwe ontwikkelingen zoals de interactieve beeldplaat. ${ }^{\mathrm{I}}{ }^{6}$ Deze voorbeelden konden de andere opdrachtfilmers niet echt overtuigen. Ook de waarschuwingen van insiders maakten weinig indruk. Zo voorspelde John M. Vijlbrief in maart I978, twee maanden nadat De telegraafhet boek van het echtpaar Brush te koop had aangeboden, in zijn column in Ariadne, het vakblad voor de reclamebranche, dat video een 'grote concurrent voor film' zou worden. ${ }^{\text {I7 }}$

Het gevolg was dat buitenstaanders in het gat sprongen. Het aantal bedrijven in de audiovisuele sector groeide dan ook snel. Begin jaren zestig telde de productiesectie van de Nederlandse Bioscoopbond drieëndertig productiebedrijven. ${ }^{18}$ Daar waren enkele 'slapende firma's' tussen, maar omdat er ook bedrijven op de opdrachtmarkt actief waren, die niet bij de NBB waren aangesloten, kan het aantal van rond de dertig als een betrouwbare schatting beschouwd worden. In I98I was het aantal bedrijven gegroeid tot maar liefst tachtig, zoals een enquête van het blad AudioVisueel duidelijk maakte. ${ }^{\text {I9 }}$ Ook de komst van verschillende van dergelijke tijdschriften die zich richtten op makers en gebruikers van voorheen ondergewaardeerde audiovisuele media als band-dia ${ }^{20}$ of video, was trouwens een teken dat er iets aan het veranderen was in het Nederlandse 'audiovisuele landschap'. ${ }^{2 \mathrm{I}}$ Wat betekende die verandering voor de opdrachtsector? Eerst komen de producenten aan bod, die lange tijd het gezicht van de Nederlandse opdrachtfilm bepaald hadden.

\section{'Oude vertrouwde' producenten}

In de jaren zeventig en tachtig werd de opdrachtsector gedomineerd door drie grote bedrijven. Allereerst was er het in Hilversum gevestigde Cinecentrum. Polygoon, Profilti en Multifilm waren in de tweede helft van de jaren vijftig uit hun standplaatsen - 's-Gravenhage voor Profilti en Haarlem voor de twee andere - naar Hilversum vertrokken, waar ze deel gingen uitmaken van Cinecentrum. Dit bedrijf was op de eerste plaats bedoeld als een dienstencentrum voor de 
televisieprogramma's van de omroepen. Cinecentrum leverde technici en apparatuur en zorgde ervoor dat het geschoten filmmateriaal zo snel mogelijk ontwikkeld werd. Daarnaast bleven de dochtermaatschappijen doen wat ze altijd al deden, zoals opdrachtfilms maken of het bioscoopjournaal produceren. Tegen de snelheid en frequentie van het nieuws op televisie kon het beroemde Polygoonjournaal overigens niet concurreren. Dat het tot in de jaren tachtig gemaakt kon worden, dankte het aan een subsidie die de rijksoverheid vanaf I964 verleende.

In de jaren zeventig nam de vraag naar film snel af. De omroepen maakten steeds vaker gebruik van elektronische registratie voor hun programma's. De leiding van Cinecentrum had geen goed antwoord op deze ontwikkeling. Met de aanschaf van een 'videotrein' van vier miljoen gulden probeerde ze weliswaar met de tijd mee te gaan, maar dit was tegen het zere been van de omroepen die video als hun domein beschouwden. ${ }^{22}$ Cinecentrum was gedwongen de trein weer van de hand te doen. Het bedrijf raakte echt in de problemen, toen de NOS in I979 aankondigde het contract over de gegarandeerde afname van filmfaciliteiten te willen opzeggen. ${ }^{23}$ Dit voornemen leidde tot artikelen in de pers en vragen in de Tweede Kamer. Ondanks de protesten zegde de NOS het contract per 3I augustus I98I op. Cinecentrum kreeg een nieuwe directeur, Rien Meyer, die van Slavenburg's Bank afkomstig was. Hij probeerde het roer om te gooien door verschillende activiteiten te initiëren, zoals video's van toneelvoorstellingen, sportmarketing en de 'Video Foto Stunt', een 'electronische video-gimmick' die op allerlei beurzen te zien was. ${ }^{24}$

Al deze versnipperde activiteiten leidden echter niet tot een gezondere bedrijfsvoering, want Cinecentrum raakte steeds verder in de rode cijfers. Er bleef niets anders over dan het Polygoon-Profilti-archief te verkopen: voor drie miljoen gulden nam de NOS alle afleveringen van het journaal over, plus alle opdrachtfilms, de films van de Nederlands-Indische Film Maatschappij alsmede de twee speelfilms die Polygoon-Profilti had geproduceerd. ${ }^{25}$ Met het Polygoonjournaal liep het vervolgens ook verkeerd af. De overheid stopte in I985 de subsidiëring en een poging om het voortaan door sponsors te laten financieren door zogeheten infomercials te maken strandde al eind I986. Toen bestond Cinecentrum overigens niet meer, het was opgegaan in het nieuwe bedrijf Meta Media, waarin behalve het Hilversumse filmcentrum, ook twee uitgeverijen, een participatiemaatschappij en enkele particulieren deelnamen. Niet lang na de oprichting van Meta Media in oktober I984 vielen de eerste ontslagen en begon de ontmanteling van wat ooit de trots van de Nederlandse film was.

Met een jaarlijkse omzet van negen miljoen gulden en tweeënveertig personeelsleden was Toonder Studio's een andere belangrijke speler in de opdrachtsector. Het bedrijf was gevestigd in Kasteel Nederhorst. Opgericht in de oorlogsjaren door de beroemde stripauteur Marten Toonder, was het bekend om zijn animatiefilms. In de jaren zeventig was Toonder Studio's uitgebreid met de legendarische poppenanimatiestudio Dollywood van Joop Geesink en met Multifilm, een bedrijf dat gespecialiseerd was in wetenschappelijke en industriële films en dat deel had uitgemaakt van Cinecentrum. Toen in I987 een grootaandeelhouder zich terugtrok, waardoor het eigen vermogen met bijna een half miljoen gulden verminderde, besloot Toonder Studio's tot een emissie van certificaten van aandeel, in de hoop hiermee anderhalf miljoen gulden binnen te halen. Het bedrijf wilde niet alleen het eigen vermogen weer op peil brengen maar ook een uitbreiding financieren die zou helpen zijn marktaandeel te 
vergroten tot vijftien procent. ${ }^{26}$ Daartoe nam Toonder Studio's van de Friese Pers Beheer BV de in Groningen gevestigde productiemaatschappij Videopress over. Hiermee kon Toonder ook op de videomarkt actief worden, die het als een echt filmbedrijf tot dan toe links had laten liggen, met uitzondering van de participatie in de 'videotrein' van Video Hilversum BV. Vervolgens kocht Toonder in 1989 ook het Eindhovense bedrijf SON, dat films en video's produceerde en facilitaire diensten leverde, op en nam het in I990 een meerderheidsbelang in het Rotterdamse audiovisuele productiebedrijf Het Kader. ${ }^{27}$

Deze expansie leverde echter niet de verwachte winst op. De Toonder Group of Companies, zoals het bedrijf nu heette, leed begin jaren '9o elk jaar verlies, wat in I993 noopte tot 'een drastische saneringsoperatie'. ${ }^{28}$ Dat nam niet weg dat Toonder nog steeds een zeer goede reputatie had, vooral dankzij de talloze internationale prijzen die het met door 'het wonderkind onder de Nederlandse bedrijfsfilmers' (De telegraaf) Pieter-Rim de Kroon geregisseerde producties binnenhaalde. ${ }^{29}$ Het vertrek van De Kroon in 1995 (hij richtte zijn eigen firma De Kroon, Wissenraet \& Associés op) was een tegenvaller voor Toonder, dat er met steeds nieuwe directeuren ook niet in slaagde rust te creëren op het managementfront. Ondanks opdrachten voor de publieke en de commerciële zenders bleef het bedrijf kwetsbaar. Een nieuwe beursgang werd afgeblazen. Kort na de millenniumwisseling hield het bedrijf op met de audiovisuele productie.

Carillon Films, de derde grote onderneming binnen de opdrachtsector, anticipeerde beter op de technologische veranderingen dan Cinecentrum en Toonder Studio's. Dit bedrijf dat in I949 was opgericht door Ted de Wit en Gerard J. Raucamp, startte bijvoorbeeld al in I967 met een afdeling die zich specialiseerde in band-dia productie. ${ }^{30}$ In 1972 verhuisde het van Rijswijk naar Amsterdam en nam de nieuwe naam Carillon Audiovisual Media BV aan. ${ }^{3 \mathrm{I}}$ Deze verwijzing naar het nieuwe audiovisuele landschap dat behalve film ook video, band-dia en andere vormen van multimedia omvatte, bleek uiteindelijk weinig gelukkig. Omdat het begrip 'audiovisual' steeds meer in de engere zin van band-dia presentatie werd gebruikt, zag Carillon zich al in 1978 gedwongen tot een volgende naamswijziging: Carillon Producers. ${ }^{32}$ Die twee woorden werden later aan elkaar gevoegd tot Carillonproducers.

Carillon, dat uit een kleine groep vaste medewerkers bestond en voor de rest met freelancers werkte, liet zich niet verleiden tot risicovolle expansies. Het bedrijf verrichtte naar eigen zeggen veel consultancy werk, waar publicitair minder eer mee te behalen viel. Zo kwam Carillon minder vaak in het nieuws dan bijvoorbeeld Toonder Studio's. De productie van Picture Holland, de eerste Nederlandse Omnimaxfilm, in I985 werd echter breed uitgemeten in de pers. ${ }^{33}$ De film had een budget van maar liefst drie miljoen gulden, gefourneerd door de NAM (Nederlandse Aardolie Maatschappij). Picture Holland ging in het voorjaar van I986 in première in het Haagse Omniversum, de enige zaal in Nederland waar het door het Canadese IMAX ontwikkelde 7omm Omnimax formaat vertoond kon worden.

Zonder ophef integreerde Carillon het nieuwe medium video in zijn activiteiten. ${ }^{34}$ Zeker in vergelijking met Cinecentrum en Toonder Studio's was het bovendien opvallend hoe zorgvuldig Carillon met de continuiteit van het bedrijf omging. Nadat Ted de Wit om gezondheidsredenen in 1978 met pensioen was gegaan, gaf de andere oprichter Gerard Raucamp in de loop van de jaren tachtig het directiestokje door aan Alewijn Dekker. Deze verbreedde einde jaren negentig 
de basis van Carillon door onder meer een samenwerking met Production People in Hilversum en met Lohman Brinkhorst \& Crew in Eindhoven aan te gaan, wat resulteerde in weer een nieuwe naam: eerst Carillon Groep, vervolgens Carillon Projects. ${ }^{35}$ Dekker zorgde er vervolgens voor dat na de millenniumwisseling Harry Arp en Cees Druijff als 'derde generatie' leiding konden geven aan een weliswaar sterk afgeslankt bedrijf dat nu onder de naam Carillon Audiovisuele Communicatie actief is en in Haarlem zetelt. ${ }^{36}$

\section{Nieuwkomers}

Opmerkelijk genoeg was geen van de bovengenoemde drie bedrijven betrokken bij de productie van videojournaals. Het waren de nieuwkomers in de opdrachtsector die geen aversie tegen video toonden en zich met succes ontfermden over de productie van videojournaals. De topper onder hen was Signum Informatieprojecten. Reclame-expert Giep Franzen van het bureau FHV/BBDO benaderde in I984 vier collega's - een grafisch ontwerper, een communicatieadviseur, een televisieregisseur en een copywriter - met het idee om een bedrijf te beginnen voor het uitvoeren van multimedia 'informatieprojecten'. ${ }^{37}$ Franzen zag drie hoofdtaken: videoproductie, informatief adverteren en interne communicatie. ${ }^{38}$ Later werd het uitgangspunt in een brochure als volgt geformuleerd: 'Onze interesse gaat (...) vooral uit naar het ontwikkelen van een goede communicatiestrategie rond kleine en grote veranderingen in bedrijven en instellingen. Gebaseerd op een duidelijke probleemstelling, een doelgroepsanalyse en inhoudelijke research. ${ }^{39}$ Hiermee sloeg het bedrijf een compleet andere toon aan dan gebruikelijk was in de opdrachtsector.

Signum Informatieprojecten werd in het voorjaar van 1985 ingeschreven in het handelsregister als een zusterorganisatie van FHV/BBDO. Oprichter Jaap Drupsteen verliet Signum binnen enkele jaren, maar daar stond in 1990 de komst van Guido van Woerkom (de latere ANWB-directeur en - zeer kortstondig - Nationale Ombudsman) tegenover, die de leiding van het bedrijf op zich nam. Van Woerkom had eerder als communicatiemanager bij Albert Heijn gewerkt en was in die hoedanigheid nauw betrokken geweest bij het door Signum geproduceerde videojournaal AH tv-journaal.

Signum slaagde erin een groot aantal belangrijke opdrachtgevers binnen te halen. Het had eerst een twintigtal en later zelfs vijfendertig mensen in dienst en maakte daarnaast gebruik van talloze freelancers. Behalve de videojournaals, waarover straks meer, produceerde Signum ook korte speelfilms. Met name de speelfilms waarvoor Patty Stenger, die in I994 bij Signum in dienst trad, de scenario's schreef en die geregisseerd werden door bekende makers als Sander Francken en Paula van der Oest, vielen regelmatig in de prijzen op de SAM-dagen. Ook produceerde Signum documentaires, voor de regie waarvan gewaardeerde makers als Kees Hin en Bernie IJdis tekenden. Tot slot maakte het een groot aantal televisieprogramma's ter begeleiding van de cursussen van Teleac, beginnende met Exotisch koken in I992. ${ }^{\circ}$

Naast deze audiovisuele producties verzorgde Signum de redactie van verschillende 'papieren' personeelsbladen (bijvoorbeeld Modescoop voor M \& S Mode) en organiseerde het grote bijeenkomsten voor bedrijven, met inzet van multimedia, zoals de Unilever jaardag. Een van de succesvolle concepten was de 'business and breakfast talkshow', waarbij een echt ontbijt werd geserveerd aan een groep mensen die door een sponsor was uitgenodigd. Gedurende het 
ontbijt behandelde televisiepresentator Ivo Niehe een onderwerp dat door de sponsor in kwestie was aangedragen. ${ }^{4 \mathrm{I}}$

Nadat Guido van Woerkom in I999 naar de ANWB was vertrokken, begon het beleid van Signum te zwalken. Eerst fuseerde het met Majoor Beishuizen, de opdrachtfirma waarmee Judith Majoor en Michiel Beishuizen sinds de tweede helft van de jaren tachtig het nodige succes hadden geoogst. Dit duo kreeg de dagelijkse leiding over wat nu Signum Beishuizen werd genoemd. ${ }^{42}$ De veelvuldig bekroonde scenarioschrijfster Patty Stenger had inmiddels het bedrijf verlaten en was voor zichzelf begonnen. ${ }^{43}$ Hierna kwam er in 2000 een nieuwe algemeen directeur, maar weldra bleek dat de synergie ontbrak. Na deze toestand enige tijd te hebben aangezien, besloot het moederbedrijf FHV/BBDO er radicaal de stekker uit te trekken en Signum op te heffen.

In I98I richtte Ab Talmon Total Video Productions op. ${ }^{44}$ Het bedrijf was in Willemstad, Noord-Brabant, gevestigd en verzorgde opdrachten voor verschillende grote bedrijven. Daarnaast maakt Total Video Productions 'point of sale' video's voor de winkelketen Blokker. Ook produceerde het bedrijf van Ab Talmon een televisieprogramma in opdracht van het modebedrijf Van Gils. Het werd uitgezonden door het Europese commerciële kanaal Super Channel en was ook te zien in vijfendertig winkels waar Van Gils kleding verkocht werd.

Rond I986 werd er steeds meer gevraagd van Total Video Productions: opdrachtgevers wilden nu ook een script zien voor hun opdrachtproducties. Daarom schakelde Talmon steeds vaker de hulp in van onderwijzer Henk Goossens voor het schrijven van een scenario, of de regie van een opdrachtfilm. Goossens zei het onderwijs vaarwel en begon een carrière van vijfentwintig jaar bij Total Video Productions en opvolgers.

Omdat het moeilijk bleek om nieuwe werknemers helemaal naar Noord-Brabant te laten komen, besloot Talmon in 1992 om met zijn bedrijf naar Dordrecht te verhuizen. Total Video Productions maakte in de jaren negentig veel videojournaals voor bedrijven. Daarnaast ontwikkelde het zusterbedrijf Talmon TV Productions in opdracht van het NMI (Nederlands Mode Instituut) een modeprogramma, Outfit, bestaande uit veertien, volledig gescripte afleveringen die in het seizoen I992-I993 door Veronica op televisie werden uitgezonden. Omdat ook Dordrecht nog een eind van de 'bewoonde audiovisuele wereld' was, deed Talmon veel in eigen huis, met eigen cameralieden, eigen geluidstechnicus en eigen studio. In I997 besloot hij toch naar de Randstad te verhuizen, naar Nieuwegein, waar zijn bedrijf negen jaar opereerde onder de naam Talmon AV-communicatie. Na een tijdje werd 'AV' overigens uit de naam weggelaten, omdat Talmon merkte - net als Carillon eerder - dat het steeds lastiger werd om uit te leggen waar dit nu precies voor stond.

In Nieuwegein werd ook de productie van dvd's, cd-roms en internetapplicaties ter hand genomen, die steeds meer de lineaire videoproducties en met name het videojournaal vervingen. Rond 2004 stak het idee van 'online storytelling' de kop op. Het bedrijf groeide in die tijd nog heel sterk en verhuisde om die reden in 2006 naar Bilthoven. Er volgde ook weer een naamswijziging: Talmon Online Storytelling. In 2008 besloot Talmon zijn bedrijf te verkopen aan een groep jonge ondernemers maar hij bleef wel aan als directeur. De aandeelhouders bleken echter veel minder geld te hebben dan Talmon aanvankelijk dacht en in 20 II ging Talmon Online Storytelling failliet. In $20 \mathrm{I} 2$ kocht Talmon het bedrijf terug om tot een herstart in 
afgeslankte vorm te komen. Het bedrijf dat nu in de creatieve broedplaats MaCloud Gallery in Bilthoven is gevestigd, bestaat sindsdien uit een klein kernteam met oude werknemers en nieuwe, jonge mensen. ${ }^{45}$

Signum en het bedrijf van Ab Talmon waren lang niet de enige nieuwe bedrijven in de opdrachtsector. Opvallend genoeg kwamen veel van hen van buiten de Randstad. Naast de bedrijven die boven al genoemd zijn (Videopress in Groningen, SON en Lohman Brinkhorst \& Crew, beide in Eindhoven), waren dit onder meer Jongenelen Video Roosendaal, Videoproductions Zuid-Limburg in Kerkrade, JBF Produkties te Groningen en Image Productions en EMK, beide in Nijmegen. Vrijwel alle genoemde bedrijven waren aangesloten bij de Verenigde Audiovisuele Produktiebedrijven (VAP). Deze vereniging was voortgekomen uit de afdeling Audiovisuele Productie van de Nederlandse Bioscoopbond maar had als geassocieerd lid een grote mate van zelfstandigheid, terwijl ze wel gebruik kon blijven maken van de secretariële ondersteuning van de bond en vertegenwoordigd bleef in haar arbitrage-commissies. De VAP voldeed duidelijk aan een behoefte in de opdrachtbranche, want eind 1989 werd al het honderdste lid geregistreerd. ${ }^{46}$

\section{Bedrijfsjournaal}

In 1978 begon de Rabobank met een eigen videojournaal, Bank in beeld, dat de bank door haar eigen audiovisuele dienst in een eigen studio in het hoofdkantoor in Eindhoven op semiprofessionele Sony U-Matic apparatuur liet produceren. ${ }^{47}$ In 1972 waren de twee voornaamste coöperatieve banken, Boerenleenbank en Raiffeisenbank, samengegaan in de Rabobank. Er was sprake van grote verschillen in bedrijfscultuur, waarvoor een oplossing gezocht moest worden. Ook breidde de bank haar productenpakket uit door onder andere reizen en verzekeringen te gaan verkopen. Tenslotte nam de automatisering een steeds hogere vlucht. Dit waren genoeg redenen om de Rabobank-medewerkers niet alleen met schriftelijk materiaal aan te spreken maar ook met een eigen 'televisieprogramma', waarmee een investering van maar liefst een half miljoen gulden gemoeid was. ${ }^{48}$ In eerste instantie werden 250 aangesloten banken voorzien van een U-Matic speler en een televisietoestel, binnen een paar jaar kregen alle I500 banken dergelijke apparatuur. ${ }^{49}$ Iedere drie maanden leverde de eigen transportdienst van de Rabobank een U-Matic cassette af met daarop de nieuwste aflevering van Bank in beeld. Het was de bedoeling dat elke aflevering door het personeel van de bank gezamenlijk bekeken werd en dat de behandelde onderwerpen vervolgens doorgesproken werden. In de vroegste afleveringen was dan ook een rollenspel opgenomen, dat door de bankmedewerkers kon worden nagespeeld.

Tussen 1978 en 1996 werden precies vierhonderd afleveringen van Bank in beeld geproduceerd. In de loop der tijd werden ze steeds korter van duur, terwijl de verschijningsfrequentie toenam. Nadat Tielemans in I993 als hoofd was opgevolgd door Tonko Tomeï, nam het aantal afleveringen nog verder toe, tot wel veertig per jaar, met een duur van tien tot twaalf minuten. Tomeï begon ook met het aantrekken van freelancers voor de productie van Bank in beeld, omdat hij van mening was dat zij een frisse blik meebrachten, die het enigszins ingeslapen productieteam hard nodig had. Voor het eerst werd ook een aftiteling aan het journaal toegevoegd. Voordien waren de namen van de medewerkers, met uitzondering van de presentatoren, anoniem. 


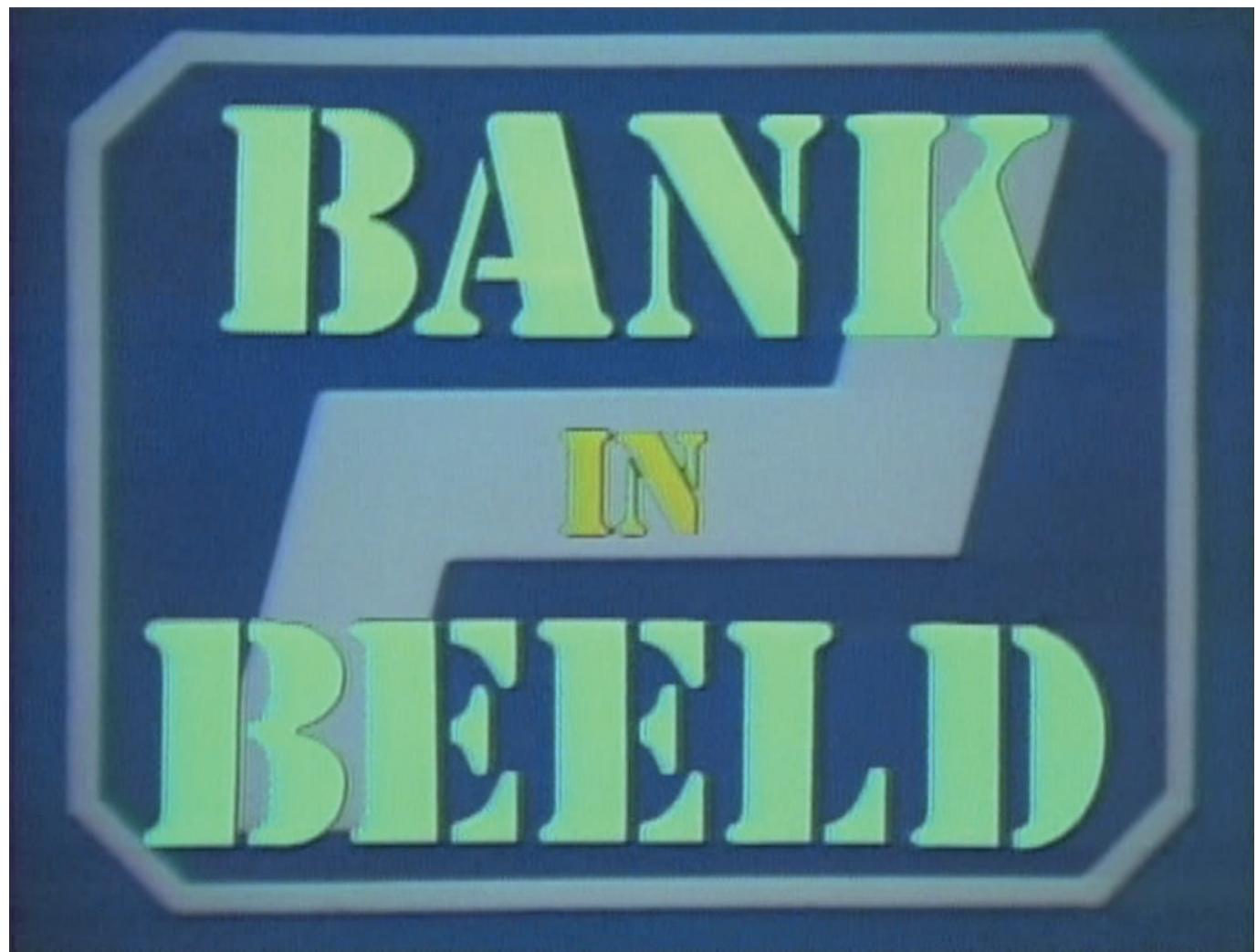

Openingsbeeld eerste aflevering Bank in Beeld. Bron: Collectie Rabobank Bedrijfshistorie. ${ }^{50}$

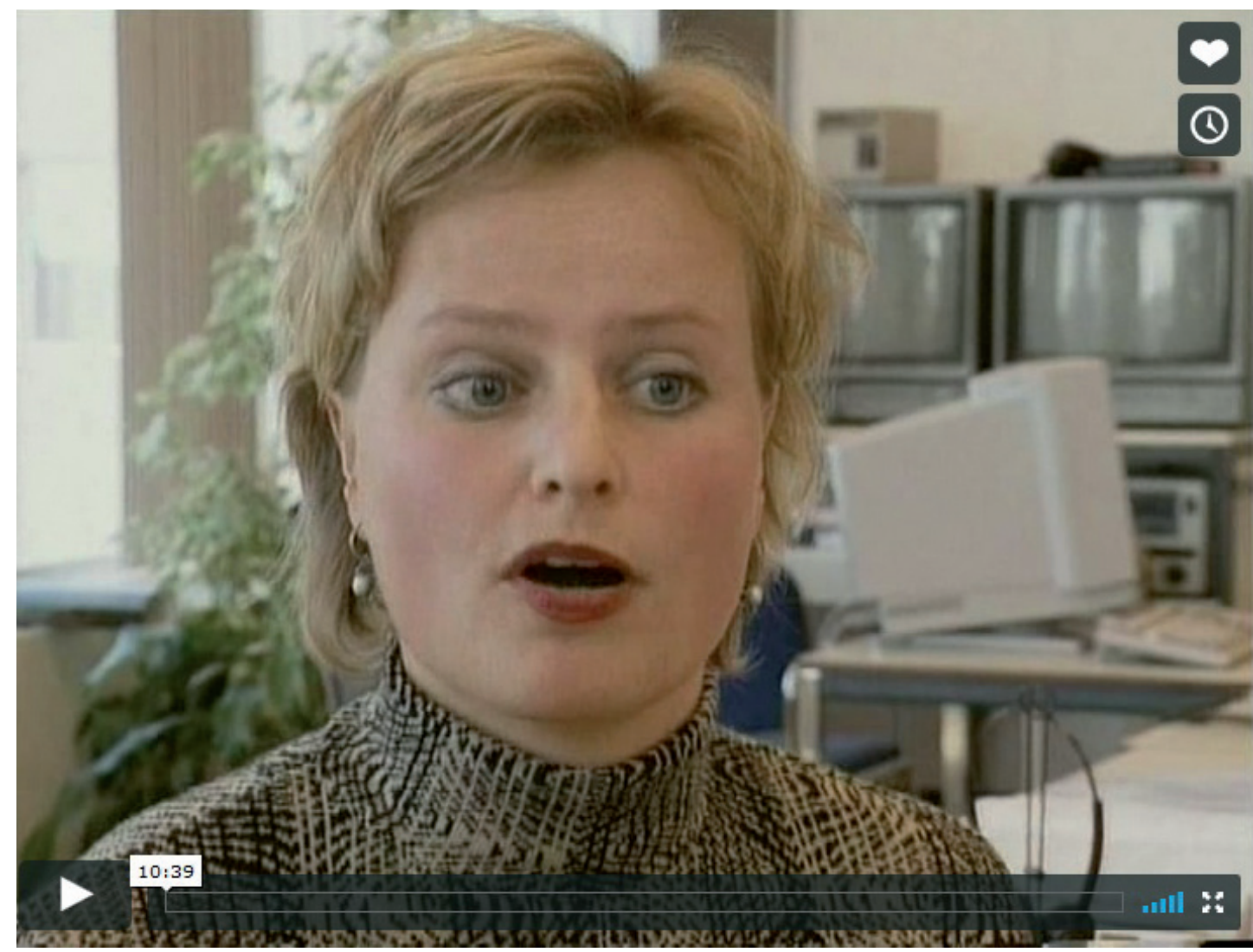

Allerlaatste aflevering van Bank in Beeld (1996) met daarin een terugblik naar de allereerste aflevering uit 1978. Bron: Collectie Rabobank Bedrijfshistorie. 
Helemaal nieuw was het fenomeen bedrijfsjournaal niet. De Schiedamse werf Wilton-Fijenoord liet al vanaf begin jaren vijftig belangrijke gebeurtenissen of interessante onderwerpen op $\mathrm{I} 6 \mathrm{~mm}$ film vastleggen door enkele personeelsleden. Uit deze opnamen werd een jaaroverzicht van een half uur tot driekwartier gemonteerd, dat bij feestelijke gelegenheden werd vertoond aan het personeel, oud-medewerkers en jongeren die belangstelling hadden voor een opleiding aan de bedrijfsschool van de werf..$^{\text {II }}$ In de jaren zestig liet ook de Staatsmijnen door Cinecentrum-dochter Profilti een eigen bedrijfsjournaal maken. Een andere Cinecentrumdochter, Multifilm, produceerde gedurende vele jaren een jaaroverzicht op film voor de stad Eindhoven. Deze bedrijfsjournaals leken sterk op het jaaroverzicht van het Polygoon-Profilti bioscoopjournaal Neerlands nieuws.

Bank in beeld vond snel navolging. De Nederlandse tak van computergigant IBM (met zes vestigingen verspreid over het land) begon eveneens in 1978 met het tweemaandelijkse IBM-videojournaal dat door eigen medewerkers werd geproduceerd. ${ }^{52}$ Ook de in Apeldoorn gevestigde verzekeringsmaatschappij Centraal Beheer produceerde zijn eigen videojournaal 'in huis'. Het werd op achttien monitoren afgespeeld die verspreid over het door architect Herman Herzberger ontworpen hoofdkantoor van de verzekeringsmaatschappij waren aangebracht. ${ }^{53}$

Het voorbeeld van de Rabobank vond ook navolging bij andere banken, die met dezelfde problemen (fusies, dislocatie, nieuwe producten en automatisering) worstelden. Alleen kozen zij er niet altijd voor om zelf hun videojournaals te produceren, maar schakelden producenten van buiten in. Dat was bijvoorbeeld het geval bij de Amro Bank die de productie van AMROvisie uitbesteedde aan het adviesbureau Imaco. ${ }^{54}$ Aan Telegraaf-journalist Jaap Deltenre vertelde Maarten Kuurman, lid van de programmaraad van de bank, waarom Amro deze keuze had gemaakt: 'Kwaliteiteitsnormen, de hoge investeringen en het feit dat de hardware snel veroudert, waren voor ons argumenten om de produktie aan specialisten over te laten. Tevens voorkomen daarmee het gevaar van bedrijfsblindheid die de creativiteit en kwaliteit kan ondermijnen. ${ }^{55}$ Overigens huurde Imaco op zijn beurt weer freelancers in voor de techniek. Net als de Rabobank koos Amro voor het relatief dure semi-professionele U-Matic formaat. Kuurman: 'Mensen kijken veel televisie en zijn kwaliteit gewend. Daarop moet je aansluiten. Als je een bedrijfsvideojournaal maakt moet je dat professioneel doen. ${ }^{56}$ In eerste instantie werden alle vijfenzestig districtskantoren en ruim tweehonderd middelgrote kantoren van een U-Matic speler voorzien.

Ook de Postbank, ontstaan uit een fusie in I986 van de Postgiro en de Rijkspostspaarbank, startte in I987 met een eigen videojournaal. Het Postbank journaal werd geproduceerd door het in Nijmegen gevestigde bedrijf Image Productions en later door de Case Communicatie Groep in De Bilt. ${ }^{57}$ Tussen I987 en I989, toen ze fuseerde met de Postbank, had ook de Nederlandse Middenstandsbank een eigen journaal, NMB-tv. Het werd door een NMB-team onder leiding van Theo van der Biessen geproduceerd op het professionele Betacam formaat dat bijvoorbeeld ook de standaard was bij de Nederlandse televisie, maar gedistribueerd op consumentenformaat in de vorm van VHS-cassettes. ${ }^{5}$

Het waren niet alleen banken die video omarmden. Behalve Centraal Beheer hadden ook andere verzekeraars, zoals de coöperatieve AVCB Groep en de AMEV, een eigen bedrijfsjournaal. 
Ook "s lands grootste kruidenier' Albert Heijn kreeg zijn eigen AH tv-journaal. Zoals Jan van Lieshout van Signum Informatieprojecten, dat het journaal voor AH produceerde, aan De telegraaf vertelde, keken 'elke maandagmorgen tussen 9 en Io uur (...) 20 duizend medewerkers in 480 supermarkten naar het AH tv-journaal. De 4000 ATV-ers en part-timers die dan vrij hebben, zien het weekjournaal op een ander tijdstip.' De U-Matic cassettes werden elke 'vrijdagmiddag bij de groentencentra van Albert Heijn afgeleverd en zaterdag, gelijk met de verse spruitjes en tomaten, aan de filiaalchefs overhandigd. ${ }^{59}$ In de jaren tachtig was de 24 uurseconomie nog toekomstmuziek en waren vrijwel alle winkels, ook die van Albert Heijn, op de vroege maandagmorgen gesloten.

Ook andere grote winkelketens zagen het nut van een eigen bedrijfsjournaal in, zoals Albert Heijn-dochter Etos. De I28 filialen van deze drogisterijketen kregen elke maand een twintig minuten durende aflevering van het door het Nijmeegse videobedrijf EMK gemaakte Etos teamjournaal. ${ }^{60}$ Hetzelfde bedrijf produceerde ook een bedrijfsjournaal voor Alberto, de slijterijketen van Albert Heijn die later op zou gaan in Gall \& Gall. M \& S Mode telde honderdvijftig filialen in Nederland, België, Luxemburg en Duitsland, die per post een exemplaar van het door Signum geproduceerde Modescoop op het handzame Video 8-formaat bezorgd kregen. ${ }^{6 \mathrm{I}}$ Ab Talmon's Total Video Productions verzorgde onder meer videojournaals voor Intratuin, de nieuwe keten van tuincentra, en voor de transportgigant Nedlloyd. Toen rode cijfers V \& D eind jaren tachtig noopten tot een fikse reorganisatie, zag de directie in bedrijfstelevisie een van de oplossingen om 'het contact met de basis te versterken'. De warenhuisketen koos voor live televisie per satelliet, waartoe alle zeventig vestigingen voorzien werden van een schotelantenne. De transmissie werd verzorgd door een dochter van PTT Telecom, met de toepasselijke naam Satellite Business Television, terwijl Cinevideo de opnameapparatuur en technici leverden. ${ }^{62}$

Hoe zagen deze bedrijfsjournaals eruit? De eerste afleveringen van Bank in beeld die ongeveer veertig minuten duurden, waren een kruising tussen een nieuwsuitzending en een actualiteitenrubriek, gepresenteerd vanachter een newsdesk dat om de zoveel jaar een nieuw jasje kreeg - zoals ook bij de televisie gebruikelijk - door Bert Tielemans, het hoofd van de audiovisuele dienst van de Rabobank, en een wisselende vrouwelijke sidekick die uit de radioof televisiewereld afkomstig was, zoals Anne van Egmond, Dieuwertje Blok of Anneke Bakker. Er waren meer journaals die door bekende namen uit de omroepwereld werden gepresenteerd. Zo was Astrid Joosten vele jaren het gezicht van het door Signum geproduceerde AMEV huisbuis. V \& D huurde Brandpunt-coryfee Aad van den Heuvel in als presentator voor haar satellietuitzendingen, waarin Karen Bloemen 'voor de vrolijke noot' zorgde. ${ }^{63}$

Bedrijfsjournaals waren ook een opstap voor aankomende talenten, zoals Wilke Durand, de vrouwelijke helft van het presentatieteam van $A H$ tv-journaal. Eind I990 verwierf zij ineens landelijke bekendheid als verpleegster Tessa van Loon in de televisieserie Medisch centrum west en hield niet lang daarna op bij het $A H$ tv-journaal. ${ }^{64}$ Durand's opvolgster, NCRVradioverslaggeefster Karin Douma, was eveneens een nieuw gezicht. Het grootste succes van het AH tv-journaal was overigens de 'razende reporter' Simon van der Ben met zijn opvallende jack waarop speciaal het logo van AH-tv was gestikt. Volgens het personeelsblad was Radio Stad Amsterdam-reporter Van der Ben in korte tijd "uitgegroeid tot het idool, de lieveling, het "scheetje" van het filiaalpersoneel. ${ }^{65}$ 
134 Tijdschrift voor Mediageschiedenis - 20 [I] $20 \mathrm{I7}$

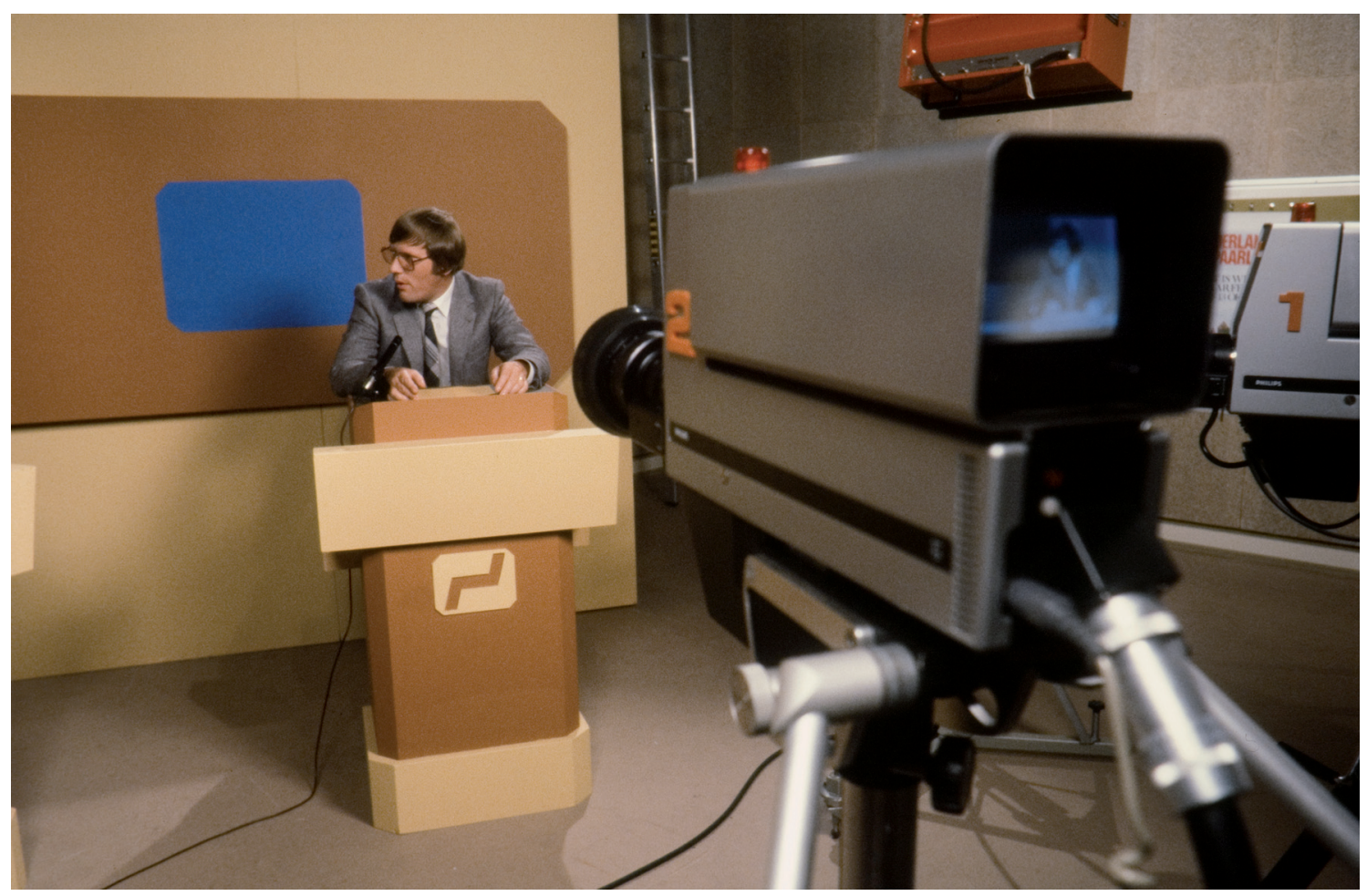

Studiofoto van opnames voor Bank in Beeld met Bert Tielemans achter de newsdesk en met een Sony videocamera. Bron: Collectie Rabobank Bedrijfshistorie.

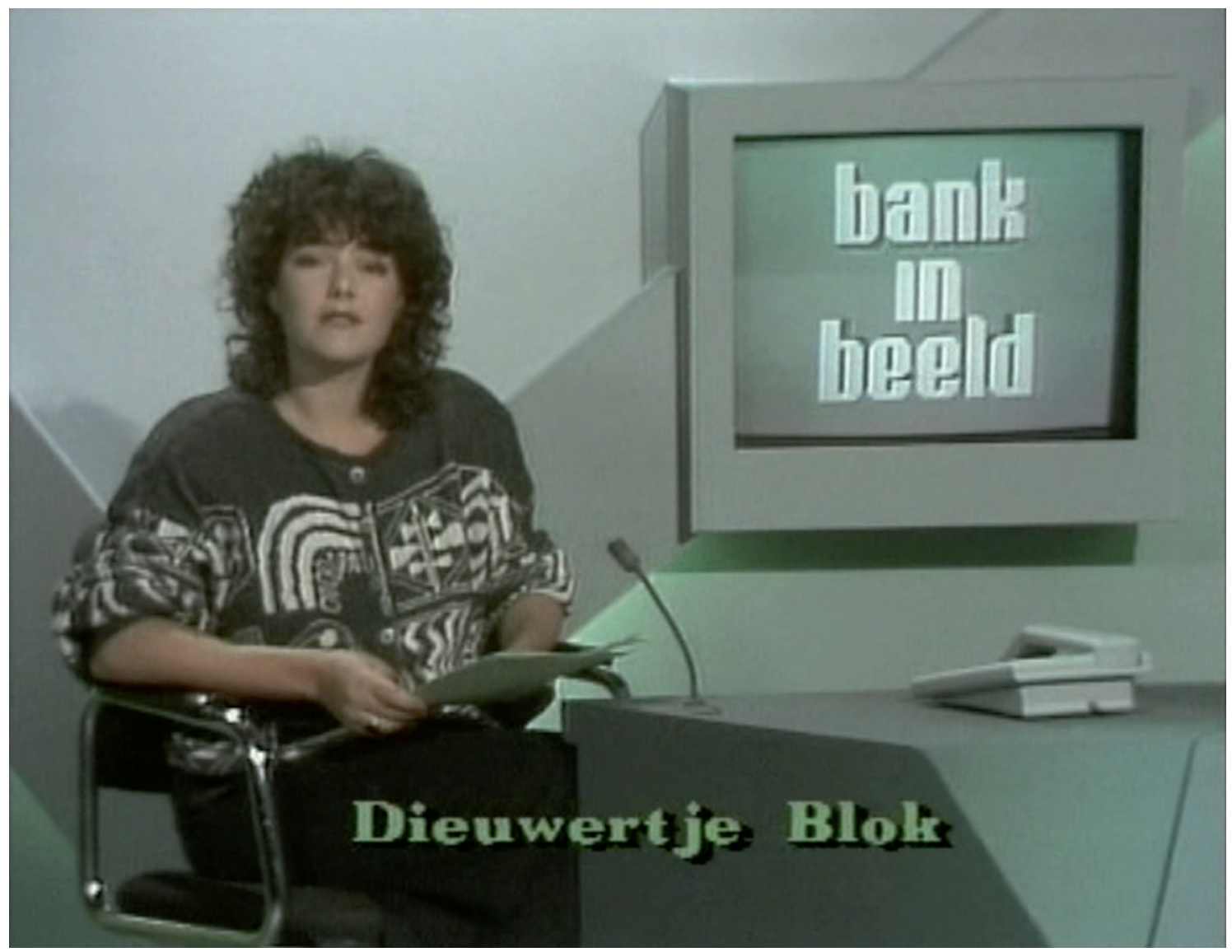

Still uit een Bank in Beeld aflevering met Dieuwertje Blok als presentatrice. Tussen 1987-1988 presenteerde zij in totaal veertien afleveringen. Bron: Collectie Rabobank Bedrijfshistorie. 
Er waren ook de nodige presentatoren die in navolging van Bert Tielemans van Bank in beeld uit het bedrijf zelf afkomstig waren en dus zonder radio- of televisie-ervaring een bedrijfsjournaal presenteerden. Zo was Caroline Braat werkzaam als directiesecretaresse bij IBM, toen ze begon met de presentatie van het videojournaal van deze computergigant. Tegen Telegraaf-journaliste Madeleine Boerma vertelde ze: 'Een “echte” televisieomroepster kent men alleen van de buis. Mij kennen ze ook in het gewone, dagelijkse kantoorleven, waardoor vergelijkingen worden gemaakt hoe je in beide situaties overkomt. ${ }^{66}$ Haar werk voor het IBMvideojournaal was voor Braat een opstap naar een carrière als producente bij Imaco en presentatrice van videojournaals voor andere bedrijven, zoals AMRO-visie.

Tot slot waren er ook enkele videojournaals, zoals het Etos team-journaal en het Albertojournaal, waarin geen presentator te zien was en volstaan werd met een voice-over. Deze twee journaals weken ook om een andere reden af van het stramien, omdat er beeldmateriaal in werd opgenomen dat niet door de producent van het journaal was opgenomen maar ter beschikking was gesteld door de leverancier van bepaalde producten. Ter geruststelling werd aan het personeel meegedeeld dat het 'daarbij niet om commercials [gaat], maar om achtergrondmateriaal. ${ }^{, 67}$

Vrijwel alle journaals bestonden uit drie tot vijf items die betrekking hadden op veranderingen in het onderhavige bedrijf. Op enkele uitzonderingen na werden ze, net als bij het journaal of de actualiteitenrubriek, vanachter een newsdesk geïntroduceerd door de presentator(en). Onderwerpen die vaak aan bod kwamen waren: nieuwe producten, automatisering, personeelsbeleid, verkiezingen voor de OR, methoden om efficiëntie te verhogen en (vooral bij de banken) bestrijding van fraude. Het rollenspel dat een terugkerend item in de vroege afleveringen van Bank in beeld was, vond verder geen navolging. Maar ook al hoefden de onderwerpen in de journaals dan niet nagespeeld te worden, het was wel degelijk de bedoeling dat het personeel elke aflevering gezamenlijk bekeek en de behandelde onderwerpen vervolgens met elkaar doorgesprak.

De belangrijkste vernieuwing betrof de snelheid waarmee het journaal het beoogde publiek bereikte. Voor Centraal Beheer was het relatief eenvoudig om de 2I00 medewerkers elke dag een nieuwe journaal te presenteren, omdat er maar één locatie was. NRC-journalist Henk van Gelder berichtte dat nieuwsvoorziening hierbij voorop stond: 'snelle reacties op alles wat met het werk van doen kan hebben, van een advertentie van de concurrentie op die ochtend en een politieke uitspraak tot en met een heftige storm, die tot een plotselinge piek in de uitkeringen kan leiden. ${ }^{68}$ De proef werd als geslaagd beschouwd en de uitzendingen die meestal niet langer dan vijf minuten duurden, werden voortgezet. Alleen werd het tijdstip van uitzending naar 'tussen de middag' verplaatst. ${ }^{6}$ De Rabobank deed in april en mei 1990 een experiment met de doorgifte per satelliet van een live nieuwsprogramma aan banken die een schotel hadden om het te ontvangen. ${ }^{70}$ Zoals we boven hebben gezien, had ook V \& D al eerder voor live televisie per satelliet gekozen.

Een terugkerende vraag behelsde het rendement van al deze inspanningen. Vaak werd als pluspunt het groepsproces aangehaald: samen naar het bedrijfsjournaal kijken bevorderde de saamhorigheid en verlaagde de drempel voor het houden van een nagesprek. Kortom, het journaal bevorderde de motivatie en betrokkenheid van het personeel. Bovendien genereerde de keuze door de directie van hun bedrijf voor zulke moderne media als video en televisie een 
zekere trots bij de werknemers. Maar er waren ook beperkingen. Journalist Henk van Gelder sprak een employé die kort en duidelijk was over het videojournaal van zijn bedrijf: 'Het is eerder interne reclame dan informatie. ${ }^{71}$ Guido van Woerkom van Signum zag de volgende nadelen:

Menselijke verhoudingen zijn in journaals buitengewoon moeilijke onderwerpen; over arbeidsconflicten of arbeidsvoorwaarden is in een videojournaal moeilijk te communiceren. In een bedrijfsjournaal kun je een algemeen verhaal houden; je kunt aangeven dát er iets gebeurt. In ondersteunend schriftelijk materiaal kan vervolgens worden verteld wat dit concreet betekent. ${ }^{72}$

Hoewel het bedrijfsjournaal door sommigen als een vervanging van het personeelsblad werd gezien (of zoals journalist Siebrand Vos het plastisch uitdrukte: "Interne video" neemt plaats in van stenciltje' $)^{73}$, pleitte Van Woerkom dus voor het naast elkaar bestaan van beide media. Niet geheel toevallig produceerde Signum zowel videojournaals als 'papieren' personeelsbladen.

Over de duurzaamheid van het videojournaal als format liet niemand zich uit. Rond de eeuwwisseling bleek dat die beperkt was, want het ene na het andere bedrijf hield op met zijn journaal. De Rabobank stopte als eerste, in I996. In I999 vroeg het blad AV prof zich af of het bedrijfsjournaal nog wel toekomst had. Aanleiding was het feit dat ook Albert Heijn ophield met het AH tv-journaal. Signum-producent Ad Krechting legde uit wat de reden was: 'Korter werken, flexibele werktijden en vooral de verlengde openingstijden zorgen ervoor dat je de ploeg niet meer op hetzelfde moment bij elkaar krijgt. ${ }^{74}$ In zekere zin had het AH tv-journaal actief meegewerkt aan zijn eigen opheffing, want al in I990 werd er bijvoorbeeld een extra aflevering uitgebracht om bij het personeel te polsen of dit op vrijwillige basis tot 18.30 u. wilde werken. ${ }^{75}$ De respons was overwegend positief en de openingstijden zouden hierna steeds verder opgerekt worden.

\section{Slot}

De keuze voor video werd in eerste instantie ingegeven door het gemak waarmee de producten door de 'eindgebruikers' bekeken konden worden. Het volstond om een cassette in de sleuf te stoppen en op de knop play te drukken. Bovendien waren de kosten voor het maken van duplicaten veel lager dan bij film. De productie van deze videojournaals kwam voor rekening van nieuwe bedrijven die zich niet schatplichtig voelden aan de traditie van de 'klassieke' opdrachtfilm, maar juist geïnspireerd werden door het in filmkringen versmade medium televisie.

Hoewel het aantal van driehonderd ondernemingen die volgens de voorspelling van Imacodirecteur A.J. van Dijk rond I987 'gebruik zullen maken van bedrijfstelevisie', bij verre na niet is gehaald, waren er wel degelijk genoeg bedrijven die voor een eigen videojournaal geporteerd waren. ${ }^{76}$ Ze hadden - al dan niet dankzij het door De telegraaf geïmporteerde boek Private Television Communications van het echtpaar Brush - van de Amerikaanse voorbeelden gehoord of zich laten overtuigen door de enthousiaste verhalen van Nederlandse early adopters als Rabobank of IBM. De ondernemingen die aan een eigen videojournaal begonnen, waren vooral 
actief waren in sectoren die in het laatste kwart van de twintigste eeuw door fusies of de introductie van nieuwe technologieën aan sterke veranderingen onderhevig waren, zoals de bankensector, het verzekeringswezen en de detailhandel. Ook speelde in de meeste gevallen een rol dat het personeel over verschillende locaties was verspreid. De - weliswaar eenmalige investering in de benodigde afspeelapparatuur (een U-Matic speler kostte bijvoorbeeld $f$ 7000) en de - regelmatig terugkerende - productiekosten van het videojournaal zelf werden door de opdrachtgevers nauwelijks als een probleem ervaren.

Wat wel als een probleem werd gezien, was het feit dat rond de millenniumwisseling het beoogde publiek van de videojournaals gefragmenteerd raakte als gevolg van korter werken, flexibele werktijden en - bij de detailhandel - verlengde openingstijden. Want de gezamenlijke kijkervaring en het 'groepjes mensen tegelijkertijd op één lijn (...) brengen' (Jan van Lieshout van Signum) waren de voornaamste troeven van het videojournaal. ${ }^{77}$ Bovendien was er een alternatief voor handen in de vorm van het nieuwe medium internet dat de mogelijkheid bood om werknemers niet alleen als individu maar ook als lid van een community te benaderen. De betrokken bedrijven moesten sowieso met dit nieuwe medium aan de slag om hun klanten te bedienen. Geruisloos verdween het ene na het andere videojournaal om in vrijwel alle gevallen te worden vervangen door een intranet, een internet netwerk dat alleen toegankelijk was voor de eigen personeelsleden. Overigens lijkt het erop dat het videojournaal een bescheiden comeback aan het maken is. Bij Albert Heijn is men bijvoorbeeld begonnen met een eigen YouTubekanaal, Onze Albert Heijn, waarop regelmatig video's geüpload worden die de huidige vlogaanpak combineren met het journaalkarakter van vroegere $A H$ tv-journaal.

Binnen de bredere context van de geschiedenis van de opdrachtfilm in Nederland bekeken, valt allereerst op dat de videojournaals voor een duidelijk gedefinieerde doelgroep bestemd waren. Bij opdrachtfilms werd immers vaak het verwijt gehoord dat het niet duidelijk was voor wie de film in kwestie was gemaakt, met als gevolg dat hij na de feestelijke première niet meer uit het blik kwam. Verder waren de artistieke aspiraties die kenmerkend waren voor veel opdrachtfilms, ver te zoeken bij de videojournaals. Met de nieuwsuitzendingen en actualiteitenrubrieken van de televisie als grote voorbeeld kan eerder gesteld worden dat journalistieke drijfveren leidend waren. Daarbij ging het natuurlijk om een 'afhankelijke' vorm van journalistiek die volledig in dienst stond van de opdrachtgever. Tot slot weken de videojournaals door hun seriekarakter af van het gebruikelijke patroon dat opdrachtproducties losstaande films waren en de producenten bij gevolg steeds weer energie moesten steken in het werven van nieuwe opdrachten. Wel kwam het voor dat opdrachtgever en productiemaatschappij dermate tevreden waren over de samenwerking, dat ook de eerstvolgende opdracht naar dezelfde uitvoerder ging maar hier konden jaren tussen zitten. De continuiteit die het videojournaal die aan de producenten bood was echter nieuw voor de opdrachtsector.

\section{Noten}

I. Siebrand Vos, “'Interne video' neemt plaats in van stenciltje,” Nieuwsblad van het noorden, I5 december I990.

2. A.F. Hartkamp, “Bedrijfsvideo”, in de rubriek 'Van horen zeggen', De telegraaf, i4 januari I978.

3. "Opdrachtfilm I974", Film, I juni i974, II.

4. Rob Perrée, "Van Agora tot Montevideo. Van video-instituten, de dingen die voorbijgaan," in De magnetische tijd. Videokunst in Nederland 1970-1985, ed. Jeroen Boomgaard en Bart Rutten (Rotterdam: NAi Uitgevers, 2003), $5 \mathrm{I}-76$, aldaar 52 . 
5. Hoewel video vooral door actiegroepen in oude stadswijken werd gebruikt in hun strijd tegen de verloedering, was er minstens een interessante uitzondering. In het Noord-Hollandse plattelandsdorp Oostwoud leende een actiegroep die van mening was dat haar ideeën over ruilverkaveling niet serieus werden genomen door de autoriteiten, videoapparatuur van een vormingscentrum en gebruikte deze om de meningen van de bewoners te peilen. Deze opmerkelijke aanpak maakte de belangstelling wakker van de KRO die er een apart televisie-item aan wijdde, Met video de boer op (4 december I972). Nederlands Instituut voor Beeld en Geluid (NIBG), DocID 27364. 6. Vgl. Dorothy Todd Hénaut, Bonnie Sherr Klein, "In the Hands of Citizens: A Video Report (I969)," Challenge for Change. Activist Documentary at the National Film Board of Canada, ed. Thomas Waugh, Michael Brendan Baker en Ezra Winton (Montreal, Kingston: McGill-Queens University Press, 2010), 24-33. Bonnie Sherr Klein, de moeder van Naomi (No Logo) Klein, maakte de I6mm film VTR-St. Jacques (I969), waarin het gebruik van video door actiegroepen in deze arme buurt van Montreal werd getoond.

7. Het gat van Nederland (3 mei I973). NIBG, DocID 28492.

8. Jan Blokker, "Basis," De volkskrant, I9 maart 1975; herdrukt in: Een poging om film weer onder de mensen te brengen (Amsterdam: Stichting Amsterdams Stadsjournaal, I976), 72.

9. Dirk Schouten was een sleutelfiguur in het ontwikkelen van ideeën over het gebruik van video in het vormingswerk en bracht zijn ervaringen samen in het boek Media Action Projects (I997). Vgl. Marjolein Verheijen, Dirk Schouten: mediadocent. Een collectie-overzicht, NAA-werkuitgave no. 24 (Hilversum: Nederlands Audiovisueel Archief, 200I).

Io. Vgl. J. Boekestijn, N. Grünfeld, B. Manschot, T. Mulder en T. van Stegeren, Iedereen is programmamaker: over de mogelijkheden van video bij lokale televisie (Amsterdam: s.n., I976); Marjan de Bruin ed., Lokale omroep als actiemiddel (Amersfoort: Uitgeverij De Horstink, I984).

II. Een van de directeuren van SFW, Willem de Vogel, voorspelde deze ontwikkelingen al in I969 in zijn artikel “Meedenken over universitaire videocentra," Registratie I, no. 2 (april I969): 2-I4.

I2. A.C. Gisolf, “Coördinatie van audiovisuele diensten. Is er een audiovisuele revolutie?” Registratie 2, no. I (januari I970): 7-I3.

I3. Vgl. Frans Crone en Piet de Kroon, "Video: een medium in ontwikkeling," Massacommunicatie, januari I975, II-24.

I4. "Hotel-tv begint in Leiden en Utrecht", Ariadne, 8 april I97I, 475.

I5. Frans van Lier, "Videocongres in Cannes: 6oo-koppig beraad op nieuwe communicatiestrategieën," Ariadne, 29 april I97I, 592-593; "Firato "7I. Start van een nieuwe dimensie in communicatie," Limburgsch dagblad, II september I97I.

I6. Thijs Chanowski, "De beeldplaat wordt volwassen," Audiovisueel Magazine 3 no. 2 (maart I982): 6-9. Zie ook “Toekomst beeldplaat in kantoorautomatisering. Video-cassette wint slag om consument,” De telegraaf, I2 juni I982; Jaap Deltenre, "Beeldplaat bedreigt bibliotheek", De telegraaf, I2 december I983; Jan Libbenga, "Het tweede leven van de compact disc," NRC handelsblad, 22 april i987.

I7. John M. Vijlbrief, "Verwachting: video grote concurrent voor film," Ariadne, 9 maart I978, 8-9.

I8. NBB Jaarverslag 1961 (Amsterdam: NBB, I962), 79, vgl. http://film-bioscoopbranche.nl/, geraadpleegd op 4 oktober 2015 .

I9. AudioVisueel I, no. 7 (september I98I): 20-24.

20. De band-dia presentatie bestond uit de vertoning van een reeks dia's met synchroon geluid, die gestuurd werden door een systeem van pulsen.

2I. Die veranderingen kwamen goed naar voren uit een enquête die het blad Communicatie techniek Q management in 1989 hield onder de opdrachtgevers. Zij makten voor 39\% van hun activiteiten op audiovisueel gebied gebruik van video, presentaties met een overhead projector scoorden 2I,3\% en band-dia presentaties $16, \mathrm{I} \%$. Film telde slechts voor 2,4\% van de activiteiten. Vgl. Niels Eeken en Paul van de Wal, "Kansen en mogelijkheden voor groeimarkt," Communicatie techniek \& management 4, no. I (maart I990): 32-35.

22. Behalve Cinecentrum participeerde ook Toonder Studio's in Video Hilversum BV, het bedrijf dat officieel de 'videotrein' aankocht. Zie "Nieuwe videotrein," Nieuwsblad van het noorden, I5 januari I974.

23. Zie Co Berkenbosch, "NOS beëindigt contract: Cinecentrum hangt aan zijden draad," De telegraaf, I3 oktober I979.

24. “Toneel op video," Nieuwsblad van het noorden, I9 maart I984; “Toneel doet mee aan "cultuurvideo," Het vrije volk, I9 maart I984; “Samenwerking," De telegraaf, 20 januari i984; “Kusjes," De telegraaf, io oktober i983; Henk J. Meier, "Reclame met lokkertjes en weggevertjes kost Nederland jaarlijks zes miljoen: kleine geschenken onderhouden de vriendschap," Nieuwsblad van het noorden, I5 oktober I983. 
25. Vgl. Bert Hogenkamp, “'In het algemeen met spoed en zo evenwichtig mogelijk te conserveren.' De lotgevallen van het Polygoon-archief," Tijdschrift voor mediageschiedenis 3, no. 2 (2000): 35-59.

26. "Expanderende Toonder Studio's naar de beurs," Limburgs dagblad, 24 juni 1987.

27. “Toonder Studio's verwachten meer winst," Leeuwarder courant, 25 september I989; “Toonder Studio's openen vestiging in Rotterdam," Het vrije volk, II januari I990.

28. “Toonder zakt verder weg in de verliezen," De telegraaf, 8 mei I993.

29. Jaap Deltenre, "Pieter-Rim gekroond tot koning bedrijfsfilms," De telegraaf, 20 mei I992.

30. "Schets van de ontwikkeling van een opdrachtfilm-produktieonderneming," Film, I6 maart I978, II.

3I. "Carillon," NRC Handelsblad, 5 april I973.

32. "Carillon Audiovisual Media heet vanaf nu: Carillon Producers," Film, 27 juli I978, 6.

33. Vgl. "Spektakelfilm NAM voor drie miljoen. Picture Holland eerste Nederlandse omnimax-rolprent," Nieuwsblad van het noorden, 20 juli 1985; Rogier van Bakel, "Omnimax zevenmijlsstap in geschiedenis cinematografie," NRC handelsblad, 22 juli i985.

34. Zo maakte Carillon een videoproductie voor de Ondernemingsraad van de ABN, OR in beeld (I985). Met video was het mogelijk het grootst mogelijke aantal personeelsleden van deze bank te bereiken teneinde 'de kandidaatstelling [voor de OR] kwalitatief en kwantitatief te verbeteren.' Hiervoor stelde de bank overigens het aanzienlijke budget van $f$ I50.000 beschikbaar. Zie Henk van Gelder, "OR te kijk," NRC handelsblad, 20 maart I985.

35. "Carillon Groep wil av-branche verder professionaliseren. Samenwerking Carillon/Production people en Lohman," AV prof, juli-augustus I999, 4; "Carillon Projects: surfen op een mooie golf. 'Machtsbolwerken zijn niet meer van deze tijd,"” AV prof, december I999, 26-27.

36. Carillon Audiovisuele Communicatie is onderdeel van de Hypsos Holding. Het bedrijf is nu in Haarlem gevestigd. Zie http://www.carillon-av.com/, geraadpleegd op II oktober 2016.

37. De vier oprichters van Signum waren: Jaap Drupsteen, die naam had gemaakt als innovatief grafisch ontwerper voor televisie, Ad Krechting, regisseur van educatieve televisieprogramma's, Jan van Lieshout, journalist en copywriter, en Alan Parfitt, communicatieadviseur.

38. Memorandum van Giep Franzen, 5 december 1984, in het persoonlijk archief van Ad Krechting, Huizen.

39. Signum. Een signalement (Amstelveen: Signum Informatieprojecten, z.d.), in het persoonlijk archief van Ad Krechting, Huizen.

40. Susanne van Velzen, "Hollandse bleekneus in exotische keuken," Nieuwsblad van het noorden, I9 oktober I993.

4I. Vgl. folder $B$ and $B$ talkshow, in het persoonlijk archief van Ab Krechting, Huizen.

42. "Nieuwe onderneming: Signum Beishuizen," AV Prof, juni I999, I6.

43. Met haar bedrijf Zee is Stenger nog steeds actief. Zij produceert vooral korte speelfilms en animatiefilms. Vgl. http://zee.nu/, geraadpleegd op 23 oktober 2016.

44. Het hierna volgende relaas van Total Video Productions en Ab Talmon is gebaseerd op Linda Roos, "Stageverslag" (Hilversum: Nederlands Instituut voor Beeld en Geluid, 20I2), 8-ı. Zie ook Bas Agterberg, "Convergent Cultures: The Disappearance of Commissioned Audiovisual Productions in The Netherlands," View. Journal of European Television History and Culture 3, no. 6 (2014), http://viewjournal.eu/index.php/view/article/view/ JETHCo69/169.

45. Zie http://www.talmon.nl/\#waarom-storytelling, geraadpleegd op 24 oktober 2016 .

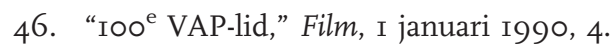

47. Klaas Samplonius, "Rabobank, voor geld en goede raad en video," AudioVisueel I. no. 3, april I980, 22-26; Bert Jongen, "Rabobank méér dan alleen Bank in Beeld," Audiovisueel magazine 4, no. 5 (juni I983): 23-24.

48. Henk van Gelder, "Ondernemingen brengen eigen nieuws op video," NRC handelsblad, 20 juni I984.

49. "Bedrijfsblad op videoband," De telegraaf, i5 mei ig82.

50. Het bedrijfsarchief van de Rabobank bevat ongeveer I900 geregistreerde audiovisuele producties; er staan er nog een paar honderd op de plank die nog ontsloten moeten worden. Van de I900 zijn er 505 bedrijfsjournaals. De serie Bank in Beeld, voor alle medewerkers, bestaat uit 400 afleveringen. Het resterende materiaal bestaat uit series gemaakt voor bestuurders en directieleden en een serie dagjournaals.

5I. Zie bijv. "Levendig journaal I96I van Wilton-F," Het vrije volk, 6 februari I962; "Boeiend filmjournaal toont Wiltons 'zeebeen'," Het vrije volk, 4 februari I966; "Hoogtepunten in bedrijfsfilm I968 van WF," Het vrije volk, 5 maart i969.

52. Madeleine Boerma, "Personeelsorgaan in vorm televisiejournaal. IBM tevreden over nieuw communicatiemiddel," De telegraaf, 26 augustus I978; Bert Jongen, "Het IBM video-journaal," Audiovisueel magazine 3, no. 6 (september I982): 8-II. 
53. Joost Hessels, "Video populair bij managers," Audiovisueel magazine 6, no. 9 (november I985): I2-I4.

54. Imaco zag begin jaren tachtig in bedrijfstelevisie een lucratieve groeimarkt. Zo voorspelde Imaco-directeur

A.J. van Dijk in I982 dat vijf jaar later "zo'n driehonderd ondernemingen gebruik zullen maken van bedrijfstelevisie.'

Zie A.J. van Dijk, "Intern communiceren via bedrijfs-t.v.," Audiovisueel magazine 3, no. 5 (juni I982): I2-I3.

55. Jaap Deltenre, “Kassie kijken in de baas z'n tijd," De telegraaf, 28 oktober I985.

56. Bert Jongen, “Amro Visie: videonet voor medewerkers en klanten," Audiovisueel magazine 5, no. 8 (november I984): 6-8.

57. Wim Kooring, "Video helpt Postbank bij communicatie en motivatie," Video Q communicatie management I, no. I (september I987): 4-5; P. van der Tuin, “Jaarverslag op video kan veel verhelderen," De telegraaf, 24 februari I993. 58. Hugo Schrameijer, "Bedrijfstelevisie: de NMB doet er ook aan mee," AV prof I, no. 2 (mei I987): 39-4I.

59. “AH Journaal oppepper winkelpersoneel," De telegraaf, 2 maart ig87.

6o. Jos van Beek, "Etos serveert bedrijfsformule bij de lunch. 'Video-journaal uitstekend communicatiemiddel'”, Video a Communicatie Management 2, no. 3 (juli I988): 2I-22.

6I. "AH Journaal oppepper winkelpersoneel".

62. "V \& D confronteert personeel met live-tv," NRC Handelsblad, 3 november I989.

63. "V \& D confronteert personeel met live-tv".

64. "Het oude en het nieuwe gezicht van AH tv," Flitsen. Personeelsblad Koninklijke Ahold nv, januari I991, 3.

65. “Simon van der Ben van AH-TV: 'Ik ben een selectief bekende Nederlander," Flitsen. Personeelsblad Koninklijke Ahold $n v$, augustus 1987, 4 .

66. Boerma, "Personeelsorgaan".

67. “Ook videojournaal bij Alberto en Etos," Flitsen. Personeelsblad Koninklijke Ahold nv, september I987, II.

68. Van Gelder, “Ondernemingen”.

69. "V \& D confronteert personeel met live-tv".

70. Stefan de Boer en Jan Frankhuizen, Een eigenzinnige reus. Veertig jaar automatisering bij de Rabobank (Utrecht: Rabobank Nederland, 2004), 55-56.

7I. Van Gelder, “Ondernemingen”.

72. Guido van Woerkom in het blad PW personeelsmanagement, geciteerd in "Bedrijfsjournaal," Leeuwarder courant, 29 augustus 1992.

73. Vos, “Interne video”.

74. "Heeft het bedrijfsjournaal nog toekomst? Flexibele werktijden bemoeilijken gezamenlijk kijkmoment," $A V$ prof, januari/februari I999, 22-23.

75. Deze extra aflevering van AH tv-journaal werd overigens niet 'gelijk met de verse spruitjes en tomaten' maar per expressepost bezorgd. Vgl. “AH wil vrijwilligers inzetten na zes uur,” NRC handelsblad, 24 april I990.

76. VanDijk, “Intern communiceren”.

77. Jaap Deltenre, “John Cleese traint bedrijven met een lach,” De telegraaf, I7 november i986.

\section{Biografie}

Bert Hogenkamp (I95I) was tot 2016 als mediahistoricus verbonden aan het Nederlands Instituut voor Beeld en Geluid. In november 20I5 nam hij afscheid als bijzonder hoogleraar aan de Vrije Universiteit Amsterdam. Hogenkamp schreef drie boeken over de geschiedenis van de documentaire film in Nederland tussen I920 en I990 en bereidt momenteel een vierde en laatste deel voor. 